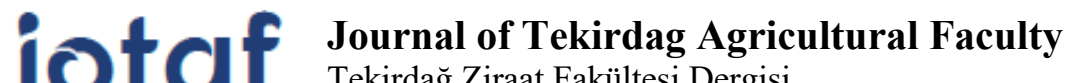

Tekirdağ Ziraat Fakültesi Dergisi

\section{Bazı Arpa (Hordeum vulgare L.) Çeşitlerinde Tuz (NaCl) Stresinin Çimlenme Özellikleri Üzerine Etkilerinin Belirlenmesi}

\author{
Determination of The Effects of Salt $(\mathrm{NaCl})$ Stress on Germination in Some Barley (Hordeum \\ vulgare L.) Varieties
}

\author{
Fevzi ALTUNER ${ }^{* *}$, Erol ORAL $^{2}$, İshak BARAN $^{3}$
}

$\ddot{\mathbf{O} z}$

Bu araştırma üç arpa (Hordeum vulgare L.) çeşidine (Kral-97: Ç1- Altıkat: Ç2 ve Larende:Ç3) uygulanan bazı $\mathrm{NaCl}$ (kontrol (0)-50-100-150-200 mM) dozlarının, tohumların çimlenme özellikleri ve fide parametreleri üzerindeki etkilerini incelemek üzere gerçekleştirilmiştir. Van Yüzüncü Y1l Üniversitesi Tarla Bitkileri Bölüm Laboratuarında 2019 yılında yürütülen bu çalışmada Faktöriyel Düzende Tesadüf Parselleri Deneme Deseni uygulanmış ve 4 tekerrürlü olarak petrilerde gerçekleştirilmiştir. Araştırmada tuz stresi altındaki arpa çeşitlerinin çimlenme gücü (\%), çimlenme oranı (\%), çimlenme indeksi (\%), ortalama çimlenme süresi (gün), hassaslık indeksi (\%), kök uzunluğu (cm), gövde uzunluğu (cm), yaş kök ağırlığı $(\mathrm{mg})$, yaş gövde ağırlığı $(\mathrm{mg})$, kuru kök ağırlı̆̆ı (mg) ve kuru gövde ağırlığı (mg) gibi çimlenme ve fide özellikleri incelenmiştir. Çalışmanın sonuçlarına göre çimlenme parametreleri yönünden; çeşitlerin sadece ortalama çimlenme indeksi ve çimlenme süresi üzerindeki etkileri ve oluşan farklar önemli bulunmuştur. Tuz dozlarının bütün çimlenme parametreleri üzerindeki etkileri ve oluşan farklar önemli bulunmuştur. Çeşitler ve $\mathrm{NaCl}$ interaksiyonlarının ise tüm parametrelerde oluşan farklar üzerindeki etkileri önemli bulunmuştur. Ortalamalara göre en düşük çimlenme gücü ve çimlenme oranlarının 150 $\mathrm{mM} \mathrm{NaCl}$ uygulamalarından alındığı ve bu nedenle bu iki özelliğin kontrole (0) göre \% 15.56 oranında düştüğü görülmüştür. Fide parametreleri yönünden, çeşitlerin gövde uzunluğu üzerindeki etkileri önemsiz,geriye kalan tüm parametreler üzerindeki etkileri önemli bulunmuşken, tuz dozlarının ve çeşitler ile $\mathrm{NaCl}$ interaksiyonlarının tüm parametrelerde oluşan farklar üzerindeki etkileri önemli bulunmuștur. Artan tuz dozlarının bütün parametreler üzerinde olumsuz etkide bulunduğu gözlenmiştir. Tuz dozu ortalamalarına göre, kontrol grubuyla kıyaslandığında tuz uygulamalarından en fazla etkilenen özelliğin ortalama çimlenme süresi (\% 82.1), en az etkilenen özelliğin ise kök yaş ağırlığı (\% 28.7) olduğu görülmüştür. Larende çeşidinin tüm özellikleri yönünden tuza daha dayanıklı bir performans gösterdiği bunu genel olarak Kral-97 çeşidinin takip ettiği tespit edilmiştir.

Anahtar Kelimeler: Hordeum vulgare L., NaCl dozları, Çimlenme özellikleri, Fide parametreleri, Abiyotik stres

\footnotetext{
1*Sorumlu Yazar/Corresponding Author: Fevzi ALTUNER, Van Yüzüncü Yıl Universitesi, Gevas MYO, Van-Türkiye. E-mail: fevzialtuner@yyu.edu.tr 1 ic OrcID: 0000-0002-2386-2450

${ }^{2}$ Erol ORAL, Van Yüzüncü Y1l Üniversitesi, Ziraat Fakültesi, Tarla Bitkileri Bölümü, Van-Turkey. E-mail: eroloral65@gmail.com (D) OrcID: 0000-0001-94131092

${ }^{2}$ İshak BARAN, Van Yüzüncü Y1l Üniversitesi, Ziraat Fakültesi, Tarla Bitkileri Bölümü. E-mail: ishakbrn571@gmail.com, (DD) OrcID: 0000-0002-6299-8043 Atıf/Citation: Altuner, F., Oral E., Baran I. Bazı Arpa ( Hordeum vulgare L. ) Çeşitlerinde Tuz (NaCl) Stresinin Çimlenme Özellikleri Üzerine Etkilerinin Belirlenmesi. Tekirdă̆ Ziraat Fakültesi Dergisi, 19 (1), 39-50.

CBu çalışma Tekirdağ Namık Kemal Üniversitesi tarafından Creative Commons Lisansı (https://creativecommons.org/licenses/by-nc/4.0/) kapsamında yayınlanmıştır. Tekirdağ 2022 


\begin{abstract}
This study was carried out on the germination properties and seedling parameters effects of some $\mathrm{NaCl}$ doses (control (0) -50-100-150-200 mM) applied to three barley (Hordeum vulgare L.) cultivars (Kral-97: V1 - Altikat: V2 and Larende: V3). The study was carried out in the Laboratory of field crops Department of the Faculty of Agriculture of Van Yuzuncu Yil University in 2019 according to the experiment two way completely randomized design in petri dishes with 4 replications. In this study, germination and seedling characteristics of the barley cultivars under salt stress such as germination power $(\%)$, germination rate $(\%)$, germination index $(\%)$, average germination time (days), sensitivity index $(\%)$, root length $(\mathrm{cm})$, stem length $(\mathrm{cm})$, fresh root weight $(\mathrm{mg})$, fresh stem weight $(\mathrm{mg})$, dry root weight $(\mathrm{mg})$ and dry stem weight $(\mathrm{mg})$ were investigated. According to results of germination parameters; the effects of cultivars on germination rate and average germination time were significant. The effects of salt doses on all germination parameters were significant. The effects of varieties and $\mathrm{NaCl}$ interactions on the differences in all parameters were significant. According to the average, the lowest germination power and germination rates were taken from $150 \mathrm{mM} \mathrm{NaCl}$ applications and therefore it was observed that these two properties decreased by $15.56 \%$ compared to control (0). The effects of salt doses and interactions between varieties and salt doses on all parameters were significant, while the effects of varieties other than hypocotyl length were insignificant and the effects on all remaining parameters were significant. Increased salt doses have been observed to have a negative effect on all parameters. According to Salt dose averages, compared to the control group, the most affected trait from salt applications was the average germination time (82.1\%) and the least affected trait was the root age weight (28.7\%). It was determined that the Larende cultivar had a more salt-resistant performance in terms of all its properties, followed by the Kral-97 variety in general.
\end{abstract}

Keywords: Hordeum vulgare L., $\mathrm{NaCl}$ doses, Germination properties, Seedling parameters, Abiotic stress 


\section{Giriş}

Geniş adaptasyon kabiliyeti nedeniyle Dünya'da ve Türkiye'de geniş bir alanda tarımı yapılan arpa, insan ve hayvan beslenmesinde önemli bir yere sahiptir (Altuner ve ark., 2018). Tanesindeki yüksek $\beta$-glukan içeriği sebebiyle besinsel lif olarak kullanılabilmesi (Altan ve ark., 2006; Ghaffarzadegan ve ark., 2018), yüksek protein içeriği nedeniyle hayvan besiciliğinde tercih edilmesi ve malt sanayinde de önemli bir hammadde olması (Taşçı ve Bayramoğlu, 2017) arpa için geniş bir kullanım alanı oluşturmaktadır. Dünya'da 46.9 milyon ha alandan 141.3 milyon ton arpa üretilirken (FAO, 2017), Türkiye'de 2.29 milyon ha alanda 6.7 milyon ton arpa üretimi yapılmaktadır (Anonim, 2017).

Arpanın tuzlu topraklara karşı yüksek toleransının (Mian ve ark., 2011) yanında, daha erkenci olması ve kuraklığa karşı direnci (Ahmed ve ark., 2016) gibi diğer tahıllara göre bir takım avantajlı yönleri bulunmaktadır (Çölkesen ve ark, 2002).

Biotik ve abiyotik olmak üzere ikiye ayrılan stres (Rejeb ve ark., 2014), bitkilerde büyüme ve gelişmeyi önemli ölçüde engellemekte özellikle çimlenme sürecinde çok olumsuz etkilerde bulunmaktadır (Yıldız ve ark., 2017; Dadaşoğlu ve Ekinci, 2013). Doğrudan etkisini osmotik ve iyon stresi oluşturarak gösteren tuzluluk (Çakmakçı ve Dallar, 2019), özellikle tuza hassas olan glikofit bitkilerin büyümesini ve verimliliğini azaltan en önemli biotik stres faktörlerinden biridir (Horie ve ark., 2012). Dünyada 831 ha tarım alanı tuzluluk problemiyle karşı karşıya iken (Metwali ve ark., 2014), Türkiye'de bu miktar 1.5 milyon hektardır (Aras ve Keskin, 2018; Demirbaş ve Balkan, 2018). Pek çok fizyolojik ve biyokimyasal olayın bozulmasına yol açan tuzluluk bitkilerde su ilişkileri, iyonik hemostazi, gaz değişimi ve mineral alımını tahrip etmektedir (Machado ve Serralheiro, 2017; Ali ve ark., 2017).

Tuza toleransı en fazla olan bitkilerden biri olduğu halde, arpa bitkisinde de tuz stresi en fazla çimlenme ve çıkış dönemlerinde olumsuz etki yapmaktadır (Kalaji ve ark., 2011; Parihar ve ark., 2015).

Tuzluluk probleminin yüksek olduğu alanlarda toleransı yüksek çeşitlerin bilinerek tercih edilmesi yüksek verim alınmasında etkili olmaktadır. Bu çalışma, Türkiye'de arpa yetiştiriciliğinde önemli olan Kral-97, Altıkat ve Larende çeşitlerinin çimlenme ve fide dönemlerinde farklı tuz dozlarına tepkilerini belirlemek üzere yapılmıştır.

\section{Materyal ve Metot}

Van Yüzüncü Yıl Üniversitesi Ziraat Fakültesi Tarla Bitkileri Bölüm Laboratuvarında 2019 yılında yürütülen bu çalışma Faktöriyel düzende Tesadüf Parselleri Deneme Deseni' ne göre 4 tekerrürlü olarak petrilerde gerçekleştirilmiştir. Çalışmada kullanılan arpalardan Kral-97 (altı sıralı) özel sektörden, Altıkat (altı sıralı) GAP Uluslararası Tarımsal Araştırma Enstitüsü’nden ve Larende (iki sıralı) Bahri Dağdaş Uluslararası Tarımsal Araştırma Enstitüsü'nden temin edilmiştir.

Araştırmada üç arpa çeşidi (Kral-97: Ç1, Altıkat: Ç2 ve Larende: Ç3), beş farklı tuz (NaCl) dozu (kontrol (0)$50-100-150$ ve $200 \mathrm{mM}$ ) ve 4 tekerrür olmak üzere toplam 60 petri kullanılmıştır. Arpa tohumları önce \% 20 (vol/vol) sodyum hipoklorid ile önce $5 \mathrm{dk}$, ardından 1 saniye süreyle \% 70'lik alkol (vol/vol) ile sterilize edilmiştir. Bunun arkasından 7 kez saf sudan geçirilerek steril kabın içinde kurumaya bırakılmıştır (Tunçtürk ve ark., 2019). Denemede tohumların nem içeriği \% 12-13 oluncaya kadar 12 saat boyunca $25 \pm 1^{\circ} \mathrm{C}^{\prime}$ de karanlık koşullarda bekletilmiştir. Bekleme süresi sonrasında tohumlar süzülüp $9 \mathrm{~cm}$ çapındaki petrilere iki kat kurutma kâğıdı yerleştirilerek aralarına 20 adet tohum konulmuştur. Daha sonra değişik derişime sahip $\mathrm{NaCl}$ solüsyonlarından $(0$, $50,150,150$ ve $200 \mathrm{mM}) 5$ doz hazırlanmış ve kontrolde kullanılan petrilerdeki tohumların su ihtiyacı için $5 \mathrm{ml}$ saf su uygulanmıştır. Bundan sonra petriler çimlenme ve çıkış testi için $20 \pm 1^{\circ} \mathrm{C}$ sıcaklıkta inkübatöre konulmuştur. Tohumların başlangıç testleri için ISTA kurallarından faydalanılmıştır (Milivojević ve ark., 2018). Çimlenmede uygulanan testler için çift katlı kurutma kağıtları arasına yerleştirilerek 4 × 20 tohum üzerinden 14 gün sürdürülmüştür (Miano ve ark., 2015).

Bu çalışmada; çimlenme oranı (\%), çimlenme gücü (\%), çimlenme indeksi (\%), ortalama çimlenme süresi $(\mathrm{cm})$, hassaslık indeksi (\%), kökçük uzunluğu $(\mathrm{cm})$, gövde uzunluğu $(\mathrm{cm})$, kökçük yaş ağırlığ $(\mathrm{mg})$, kökçük kuru ağırlığı $(\mathrm{mg})$, gövde yaş ağırlığı $(\mathrm{mg})$ ve gövde kuru ağırlığı $(\mathrm{mg})$ değerleri tespit edilmiştir. Petrilere tohumların ekiminden 7 gün sonra çimlenme oranı, 14 gün sonra ise çimlenme gücü belirlenmiştir. Yaş örnekler firında $70^{\circ} \mathrm{C}$ sıcaklıkta 24 saat kurutulduktan sonra kuru kök ve kuru gövde ağırlıkları bulunmuştur (Tunçtürk ve ark, 2019). 
Bazı Arpa ( Hordeum vulgare L. ) Çeşitlerinde Tuz ( $\mathrm{NaCl}$ ) Stresinin Çimlenme Özellikleri Üzerine Etkilerinin Belirlenmesi

Çimlenme oranı (ÇO) için (Eş.1), Akıncı ve Çalışkan (2010), çimlenme indeksi (Çİ) için (Eş.2), Kumar ve ark., (2013), ortalama çimlenme süreleri (OÇS) için (Eş.3), Park ve ark. (2013) ve hassaslık indeksi (HI) içinse (Eş.4), Askari ve ark. (2016) eşitlikleri kullanılmıştır.

ÇO $=14$ gün sonra çimlenen tohum miktarl/Ekilen toplam tohum sayısı.

(Eş.1).

ÇI $=\Sigma$ (Günlük çimlenen tohum oranı/Gün sayısı)

$O C ̧ S=\Sigma(f x) / \Sigma f \quad f=$ çimlenen tohumların sayısı, $x=$ çimlenme süresi

$H \dot{I}=$ OÇS (tuz uygulamalarında) / OÇS (kontrol uygulamalarında)

Verilerin istatistiki analizleri için COSTAT (sürüm 6.303) paket programı kullanılmış ve çoklu karşılaştırmaları ise LSD (0.05) testi ile belirlenmiştir (Düzgünes ve ark. 1987; Tunçtürk ve ark., 2019).

\section{Araştırma Sonuçları ve Tartışma}

Üç arpa çeşidinin (Ç1, Ç2 ve Ç3) tohumlarına uygulanan beş tuz (kontrol (0)-50-100-150 ve $200 \mathrm{mM})(\mathrm{NaCl})$ dozlarının bitkilerde çimlenme ve fide özellikleri üzerine etkileri incelenmiş ve sonuçları aşağıda tartışılmıştır.

\section{1. Çimlenme özellikleri üzerine etkileri}

Arpa çeşitlerine uygulanan tuz $(\mathrm{NaCl})$ dozlarının bazı çimlenme parametreleri üzerine etkileri Tablo 1'de görülmektedir. Buna göre çeşitlerin sadece çimlenme indeksi ve ortalama çimlenme süresi üzerindeki etkileri önemli olarak belirlenmiştir. Tuz $(\mathrm{NaCl})$ dozlarının ve Ç x NaCl interaksiyonlarının ise bütün çimlenme özellikleri üzerine etkileri önemli bulunmuştur.

\subsection{1. Çimlenme oranı ve çimlenme gücü üzerine etkileri (\%)}

Çimlenme oranı ve çimlenme gücü verileri aynı şekilde oluştuğu için birlikte değerlendirilmiştir. Tablo I'e göre çeşitlerin ortalamalarına göre çimlenme güçleri ve çimlenme oranları arasındaki farklar önemsiz bulunmuştur.

Tuz $(\mathrm{NaCl})$ dozları ortalamalarına göre çimlenme oranları ve güçleri arasındaki fark önemli bulunmuştur. Buna göre çimlenme oranı ve gücü \%84.44-\%100 arasında gerçekleşmiş ve en yüksek kontrol (0), 50 ve $100 \mathrm{mM} \mathrm{NaCl}$ dozları aynı istatistiki grupta yer alırken, en düşük $150 \mathrm{NaCl}$ dozundan alınmıştır. Kontrol (0) doz ortalamasına göre çimlenme oranı ve gücünün $150 \mathrm{mM} \mathrm{NaCl}$ uygulamasında ortalama olarak \% 15.56 oranında düştüğü görülmektedir.

Ç x NaCl interaksiyonlarına göre çimlenme oranı ve gücü arasındaki farklar önemli bulunmuştur. En düşük interaksiyon Larende (Ç3) çeşidine $150 \mathrm{mM}$ tuz uygulamasından (\% 85) alınırken, Altıkat (Ç2) çeşidinde $200 \mathrm{mM}$ tuz uygulaması dışındaki tüm interaksiyonlar en yüksek seviyede gerçekleşmiştir.

Çalışmamızda tespit edilen artan $\mathrm{NaCl}$ konsatrasyonlarıyla çimlenme oranı ve gücünün düştüğü Güngör ve ark. (2017), Doğan ve Budaklı Çarpıcı (2016) ve Öner ve ark. (2018) tarafından da ifade edilmiştir. Bunun yanısıra artan tuz dozlarının tohum canlılığını olumsuz yönde etkileyerek çimlenme oranı ve gücünü düşürdüğü bildirilmektedir (Güldüren ve Elkoca, 2012).

\subsubsection{Ortalama çimlenme süresi üzerine etkileri (gün)}

Tablo 1'de çeşitlerin ortalamalarına göre ortalama çimlenme süreleri arasındaki farklar önemli bulunmuştur. Buna göre ortalama çimlenme süreleri 3.24-3.52 gün arasında gerçekleşmiş ve en yüksek seviyede Kral 97 (Ç1) ve Larende (Ç3) çeşitleri aynı istatistiki grupta yer almış, en düşük ise Altıkat (Ç2) çeşidinde tespit edilmiştir. Çeşitlerin ortalamalarına göre Kral-97 ve Larende çeşitlerinin ortalama çimlenme performanslarının Altıkat çeşidine göre daha yüksek olduğu görülmektedir.

Tuz $(\mathrm{NaCl})$ dozları ortalamalarına göre ortalama çimlenme süreleri arasındaki fark önemli bulunmuştur. Buna göre ortalama çimlenme süreleri 3.13-3.81 gün arasında gerçekleşmiş ve en yüksek ortalama çimlenme süresi 200 $\mathrm{NaCl}$ dozunda, en düşük ortalama çimlenme süresi ise kontrol (0) dozunda gerçekleşmiştir. Tuz dozları ortalamalarına göre en uzun ortalama çimlenme süresi $200 \mathrm{mM} \mathrm{NaCl}$ uygulamasından alınmış ve bu süre kontrol (0) uygulamasına göre \% 17.8 daha uzun gerçekleşmiştir. 
Ç x NaCl interaksiyonlarına göre çimlenme güçleri arasındaki farklar önemli bulunmuştur. En kısa çimlenme süresi interaksiyonu Altıkat (Ç2) çeşidinin kontrol uygulamasında (3.05 gün) ve en uzun Larende (Ç3) çeşidine $200 \mathrm{mM}$ tuz uygulamasından (4.02 gün) alınmıştır.

Tablo 1. Arpa (Hordeum vulgare L.) çeşitlerinde tuz stresinin çimlenme özellikleri üzerine etkisi

Table 1. The effect of salt stress on germination characteristics of barley (Hordeum vulgare L.) cultivars.

\begin{tabular}{|c|c|c|c|c|c|c|}
\hline Çeşitler & $\begin{array}{c}\text { Stres } \\
\text { Uygulamaları } \\
\text { Tuz Dozları } \\
\text { (mM) } \\
\end{array}$ & $\begin{array}{c}\text { Çimlenme } \\
\text { Gücü } \\
(\%)\end{array}$ & $\begin{array}{c}\text { Çimlenme } \\
\text { Oranı } \\
(\%)\end{array}$ & $\begin{array}{c}\text { Çimlenme } \\
\text { İndeksi } \\
(\%)\end{array}$ & $\begin{array}{c}\text { Ortalama } \\
\text { Çimlenme } \\
\text { Süresi (gün) }\end{array}$ & $\begin{array}{c}\text { Hassaslık } \\
\text { İndeksi } \\
(\%)\end{array}$ \\
\hline \multirow{5}{*}{ Ç1 } & Kontrol (0) & $100.00 \mathrm{a}$ & $100.00 \mathrm{a}$ & $6.41 \mathrm{a}$ & $3.18 \mathrm{de}$ & 0.00 \\
\hline & 50 & $100.00 \mathrm{a}$ & $100.00 \mathrm{a}$ & $6.21 \mathrm{a}$ & $3.30 \mathrm{de}$ & $1.036 \mathrm{de}$ \\
\hline & 100 & $100.00 \mathrm{a}$ & $100.00 \mathrm{a}$ & $5.89 \mathrm{~b}$ & $3.50 \mathrm{~d}$ & $1.098 \mathrm{c}$ \\
\hline & 150 & $83.33 \mathrm{~d}$ & $83.33 \mathrm{~d}$ & $4.64 \mathrm{f}$ & $3.68 \mathrm{c}$ & $1.157 \mathrm{~b}$ \\
\hline & 200 & $95.33 \mathrm{a}$ & $95.33 \mathrm{a}$ & $4.74 \mathrm{e}$ & $3.92 \mathrm{~b}$ & $1.230 \mathrm{a}$ \\
\hline $\begin{array}{c}\text { Ç1 } \\
\text { Ortalama } \\
\end{array}$ & & 95.73 & 95.73 & 5.58 B & $3.52 \mathrm{~A}$ & 1.130 \\
\hline \multirow{5}{*}{ Ç2 } & Kontrol (0) & $100.00 \mathrm{a}$ & $100.00 \mathrm{a}$ & $6.58 \mathrm{a}$ & $3.05 \mathrm{e}$ & 0 \\
\hline & 50 & $100.00 \mathrm{a}$ & $100.00 \mathrm{a}$ & $6.41 \mathrm{a}$ & $3.17 \mathrm{de}$ & $1.038 \mathrm{de}$ \\
\hline & 100 & $100.00 \mathrm{a}$ & $100.00 \mathrm{a}$ & $6.41 \mathrm{a}$ & $3.18 \mathrm{de}$ & $1.042 \mathrm{~d}$ \\
\hline & 150 & $85.00 \mathrm{c}$ & $85.00 \mathrm{c}$ & $4.49 \mathrm{~g}$ & $3.33 \mathrm{de}$ & $1.094 \mathrm{c}$ \\
\hline & 200 & $91.67 \mathrm{~b}$ & $91.67 \mathrm{~b}$ & $4.97 \mathrm{~d}$ & $3.48 \mathrm{~d}$ & $1.143 \mathrm{~b}$ \\
\hline $\begin{array}{c}\text { Ç2 } \\
\text { Ortalama }\end{array}$ & & 95.33 & 95.33 & $5.77 \mathrm{~A}$ & $3.24 \mathrm{~B}$ & 1.079 \\
\hline \multirow{5}{*}{ Ç3 } & Kontrol (0) & $100.00 \mathrm{a}$ & $100.00 \mathrm{a}$ & $6.42 \mathrm{a}$ & $3.15 \mathrm{de}$ & 0 \\
\hline & 50 & $100.00 \mathrm{a}$ & $100.00 \mathrm{a}$ & $6.27 \mathrm{a}$ & $3.20 \mathrm{de}$ & $1.016 \mathrm{e}$ \\
\hline & 100 & $100.00 \mathrm{a}$ & $100.00 \mathrm{a}$ & $6.15 \mathrm{a}$ & $3.30 \mathrm{de}$ & $1.049 \mathrm{~d}$ \\
\hline & 150 & $85.00 \mathrm{c}$ & $85.00 \mathrm{c}$ & $4.39 \mathrm{~h}$ & $3.28 \mathrm{de}$ & $1.042 \mathrm{~d}$ \\
\hline & 200 & $100 \mathrm{a}$ & $100 \mathrm{a}$ & $5.23 \mathrm{c}$ & $4.02 \mathrm{a}$ & $1.036 \mathrm{de}$ \\
\hline $\begin{array}{c}\text { Ç3 } \\
\text { Ortalama }\end{array}$ & & 97 & 97 & $5.69 \mathrm{AB}$ & $3.39 \mathrm{~A}$ & 1.036 \\
\hline \multirow{5}{*}{$\begin{array}{l}\text { Tuz*** } \\
\text { Dozları } \\
\text { Ortalama } \\
(\mathbf{m M})\end{array}$} & Kontrol (0) & $100 \mathrm{~A}$ & $100 \mathrm{~A}$ & $6.471 \mathrm{~A}$ & $3.127 \mathrm{D}$ & 0 \\
\hline & 50 & $100 \mathrm{~A}$ & $100 \mathrm{~A}$ & $6.295 \mathrm{AB}$ & $3.222 \mathrm{CD}$ & $1.030 \mathrm{C}$ \\
\hline & 100 & $100 \mathrm{~A}$ & $100 \mathrm{~A}$ & $6.154 \mathrm{~B}$ & $3.327 \mathrm{BC}$ & $1.064 \mathrm{BC}$ \\
\hline & 150 & $84.444 \mathrm{C}$ & $84.444 \mathrm{C}$ & $4.506 \mathrm{D}$ & $3.433 \mathrm{~B}$ & $1.098 \mathrm{~B}$ \\
\hline & 200 & $95.666 \mathrm{~B}$ & $95.666 \mathrm{~B}$ & $4.983 \mathrm{C}$ & $3.805 \mathrm{~A}$ & $1.216 \mathrm{~A}$ \\
\hline CV (\%) & & 3.961 & 3.961 & 3.772 & 5.147 & 7.203 \\
\hline LSD $_{0.05}$ & & 3.661 & 3.661 & 0.21 & 0.17 & 0.06 \\
\hline
\end{tabular}

Ç1: Kral 97, Ç2: Altıkat, Ç3: Larende.

*Ortalamalar arasındaki fark LSD (0.05) çoklu karşılaştırma metoduyla $\mathrm{P}<0.05$ seviyesinde değerlendirilmiştir. Aynı sütunda aynı harfle gösterilen ortalamalar arasında istatistiki olarak bir fark yoktur.

**Tuz $(\mathrm{NaCl})$ dozları ortalamalarının aynı sütunda aynı harfle gösterilen değerleri arasında istatistiki olarak bir fark yoktur.

\subsection{3. Çimlenme indeksi üzerine etkileri (\%)}

Tablo l'e göre çeşitlerin ortalamalarına göre çimlenme indeksleri arasındaki farklar önemli bulunmuştur. Çimlenme indeksi en yüksek Altıkat çeşidinde (\% 5.77) ve en düşük Kral 97 çeşidinde (\% 5.58) gerçekleşmiştir.

Tuz $(\mathrm{NaCl})$ dozları ortalamalarına göre çimlenme indeksleri arasındaki fark önemli bulunmuştur. Buna göre çimlenme indeksleri \%4.506-\%6.471 arasında gerçekleşmiş ve en yüksek çimlenme indeksi kontrol (0) dozundan alınırken, en düşük $150 \mathrm{NaCl}$ dozunda belirlenmiştir. Kontrol (0) doz ortalamasına göre çimlenme indeksinin 150 mM NaCl uygulamasında \% 69.6 oranında düştüğü görülmektedir. 
Ç x NaCl interaksiyonlarına göre çimlenme indeksleri arasındaki farklar önemli bulunmuştur. En düşük çimlenme indeksi Larende (Ç3) çeşidine $150 \mathrm{mM}$ tuz uygulamasından (\% 4.39) alınırken Kral 97 (Ç1) çeşidine kontrol ve $50 \mathrm{mM}$ ile Altıkat (Ç2) ve Larende (Ç3) çeşitlerine kontrol, $50 \mathrm{mM}$ ve $100 \mathrm{mM}$ tuz uygulamaları en yüksek grupta yer almıştır.

\subsubsection{Hassaslık indeksi üzerine etkileri (\%)}

Tablo l'e göre çeşitlerin ortalamalarına göre hassaslık indeksleri arasındaki farklar önemsiz bulunmuştur.

Tuz $(\mathrm{NaCl})$ dozları ortalamalarına göre hassaslık indeksleri arasındaki fark önemli bulunmuştur. Buna göre hassaslık indeksleri \%1.03-\%1.22 arasında gerçekleşmiş ve en yüksek hassaslık indeksi $200 \mathrm{mM} \mathrm{NaCl} \mathrm{dozundan}$ alınırken, en düşük $50 \mathrm{NaCl}$ dozundan elde edilmiştir. $50 \mathrm{mM} \mathrm{NaCl}$ ortalamasına göre hassaslık indeksinin 200 $\mathrm{mM} \mathrm{NaCl}$ uygulamasında ortalama olarak \% 15.3 oranında arttığı görülmektedir.

Ç x NaCl interaksiyonlarına göre çimlenme güçleri arasındaki farklar önemli bulunmuştur. Hassaslık indeksleri en yüksek Kral 97 (Ç1) çeşidine 200 mM tuz uygulamasından (\% 1.23) ve en düşük Larende (Ç3) çeşidine 50 mM tuz interaksiyonundan (\% 1.02) elde edilmiştir.

Araştırmamızda tespit edildiği şekilde artan tuz konsantrasyonlarının hassaslık indeksini olumsuz etkilediği, Sanam ve ark. (2014) ve Tunçtürk ve ark. (2019) tarafindan da belirlenmiştir.

\subsection{Fide parametreleri üzerine etkileri}

Arpa çeşitlerine uygulanan tuz $(\mathrm{NaCl})$ dozlarının bazı fide parametreleri üzerine etkileri Tablo 2'de görülmektedir. Buna göre çeşitlerin gövde uzunlukları üzerine etkileri hariç ( $\mathrm{p}>0.05)$, çeşitlerin (geriye kalan tüm özellikler), tuz dozlarının ve $\mathrm{C} \times \mathrm{NaCl}$ interaksiyonlarının bütün fide özellikleri üzerine etkileri önemli bulunmuştur.

\subsubsection{Kök uzunluğu (cm)}

Tablo 2'ye göre çeşitlerin ortalamalarına göre kök uzunlukları arasındaki farklar önemli bulunmuştur. Çeşitlerin kök uzunlukları ortalamaları $5.79-7.31 \mathrm{~cm}$ arasında gerçekleşmiş ve Ç1-Ç3 aynı istatistiki grupta yer almıştır. En yüksek kök uzunluğu Ç1-Ç3, en düşük ise Ç2 çeşit ortalamalarından alınmıştır. Bu durumda Kral-97 ve Larende çeşitlerinin ortalama kök uzunlukları performansı Altıkat çeşidine göre \% 20 daha fazla gerçekleşmiştir.

Tuz $(\mathrm{NaCl})$ dozları ortalamalarına göre kök uzunlukları arasındaki fark önemli bulunmuştur. NaCl dozlarına göre kök uzunlukları ortalamaları 3.93-9.65 cm arasında gerçekleşmiş ve kök uzunlukları en yüksek kontrol (0) dozundan, en düşük $200 \mathrm{NaCl}$ dozundan alınmıştır. Kök uzunlukları, $200 \mathrm{mM} \mathrm{NaCl}$ dozunda kontrol (0) grubuna göre \% 59.3 oranında düşmüştür.

Ç x NaCl interaksiyonlarına göre kök uzunlukları arasındaki farklar önemli bulunmuştur. Kök uzunlukları 2.95-10.24 cm arasında gerçekleşirken en yüksek Ç1- kontrol (0), en düşük Ç2-150 mM NaCl interaksiyonundan elde edilmiştir. En yüksek doz olan $200 \mathrm{mM} \mathrm{NaCl}$ uygulamalarında Larende çeşidi aynı istatistiki grupta yer alan Kral-97 ve Altıkat çeşitlerinden \% 48.3 daha kök uzunluğu gerçekleştirmiştir.

\subsubsection{Gövde uzunluğu (cm)}

Tablo 2'ye göre çeşitlerin ortalamalarına göre gövde uzunlukları arasındaki farklar önemsiz bulunmuştur. Tuz $(\mathrm{NaCl})$ dozları ortalamalarına göre gövde uzunlukları arasındaki farklar önemli bulunmuştur. NaCl dozlarına göre gövde uzunlukları ortalamaları 3.85-11.29 cm arasında gerçekleşmiş ve gövde uzunlukları en yüksek kontrol (0) dozundan, en düşük $200 \mathrm{NaCl}$ dozundan alınmıştır. Tuz dozları ortalamalarına göre gövde uzunlukları, $200 \mathrm{mM}$ $\mathrm{NaCl}$ dozunda kontrol (0) grubuna göre \% 65.9 oranında düşmüştür.

Ç x NaCl interaksiyonlarına göre gövde uzunlukları arasındaki farklar önemli bulunmuştur. Gövde uzunlukları 2.84-11.64 cm arasında gerçekleşirken en yüksek Ç1- kontrol (0), en düşük Ç2-200 mM NaCl interaksiyonundan elde edilmiştir. En yüksek doz olan 200 mM NaCl uygulamalarında Larende çeşidi Altıkat çeşidinden \% 40.8 daha fazla gövde uzunluğuna sahip olmuştur. 


\subsubsection{Yaş kök ăğılı̆̆ı (mg)}

Tablo 2'ye göre çeşitlerin ortalamalarına göre yaş kök ağırlıkları arasındaki farklar önemli bulunmuştur. Çeşitlerin yaş kök ağırlık ortalamaları 0.78-1.035 mg arasında gerçekleşmiş ve Ç1-Ç3 aynı istatistiki grupta yer almıştır. En yüksek yaş kök ağıllığ Ç1-Ç3, en düşük ise Ç2 çeşit ortalamalarından alınmıştır. Çeşit ortalamalarına göre aynı istatistiki grupta yer alan Kral-97 ve Larende çeşitlerinin yaş kök ağırlıkları Altıkat çeşidinden yaklaşık olarak \%21.9 daha fazla gerçekleşmiştir.

Tuz $(\mathrm{NaCl})$ dozları ortalamalarına göre yaş kök ağırlıkları arasındaki fark önemli bulunmuş̧tur $\mathrm{NaCl}$ dozlarına göre yaş kök ağırlık ortalamaları 0.51-1.37 mg arasında gerçekleşmiş ve yaş kök ağırlıkları en yüksek kontrol (0) dozundan, en düşük $200 \mathrm{NaCl}$ dozundan alınmıştır. Tuz dozları ortalamalarına göre yaş kök ağırlıkları, $200 \mathrm{mM}$ $\mathrm{NaCl}$ dozunda kontrol (0) grubuna göre \% 73.8 oranında düşmüştür.

Ç x NaCl interaksiyonlarına göre yaş kök ağırlıkları arasındaki farklar önemli bulunmuştur. Yaş kök ağırlıkları 0.189-1.49 mg arasında gerçekleşirken, en yüksek aynı grupta yer alan Ç1- kontrol (0) ve Ç1-50 mM NaCl en düşük yine aynı grupta yer alan Ç2-200 mM NaCl ve Ç3-150 mM NaCl interaksiyonlarından alınmıştır. En yüksek doz olan $200 \mathrm{mM} \mathrm{NaCl}$ uygulamasında Larende çeşidi Altıkat çeşidinden \% 77.0 daha fazla yaş kök ağırlı̆̆ oluşturmuş̧ur.

\subsubsection{Yaş gövde ağırlı̆̆ $(\mathrm{mg})$}

Tablo 2'ye göre çeşitlerin ortalamalarına göre yaş gövde ağırlıkları arasındaki farklar önemli bulunmuştur. Çeşitlerin yaş gövde ağırlık ortalamaları 1.30-1.52 mg arasında gerçekleşmiş ve Ç1-Ç2 aynı istatistiki grupta yer almıştır. En yüksek yaş gövde ağırlığı Ç1-Ç2, en düşük ise Ç3 çeşit ortalamalarından alınmıştır. Çeşit ortalamalarına göre Larende çeşidinin yaş kök ağırlı̆̆ı aynı istatistiki grupta yer alan Kral-97 ve Altıkat çeşitlerinden yaklaşık olarak \%12.8 daha fazla gerçekleşmiştir.

Tuz $(\mathrm{NaCl})$ dozları ortalamalarına göre yaş gövde ağırlıkları arasındaki fark önemli bulunmuştur. $\mathrm{NaCl}$ dozlarına göre yaş gövde ağırlık ortalamaları 0.86-2.09 mg arasında gerçekleşmiş ve en yüksek kontrol (0) dozundan, en düşük aynı grupta yer alan 150-200 mM NaCl dozundan elde edilmiş̧ir. Tuz dozları ortalamalarına göre yaş gövde ağırlıkları, aynı istatistiki grupta yer alan 150 ve $200 \mathrm{mM} \mathrm{NaCl}$ dozlarında kontrol (0) grubuna göre yaklaşık olarak \% 57.4 oranında düşmüştür.

Ç x NaCl interaksiyonlarına göre yaş gövde ağırlıkları arasındaki farklar önemli bulunmuştur. Yaş gövde ağırlıkları 0.54-2.33 mg arasında gerçekleşirken, en yüksek Ç3- kontrol (0), en düşük Ç2-200 mM NaCl interaksiyonlarından alınmıştır. Çeşit x NaCl interaksiyonlarına göre Larende çeşidinin yaş gövde ağırlı̆̆ $200 \mathrm{mM}$ $\mathrm{NaCl}$ uygulamasında Altıkat çeşidinin aynı dozundan \%56.3 daha fazla gerçekleşmiştir.

\subsubsection{Kuru kök ağırlı̆̆g (mg)}

Tablo 2'ye göre çeşitlerin ortalamalarına göre kuru kök ağırlıkları arasındaki farklar önemli bulunmuştur. Çeşitlerin kuru kök ağırlık ortalamaları 0.104-0.131 mg arasında gerçekleşmiş ve Ç2-Ç3 aynı istatistiki grupta yer almıştır. En yüksek kuru kök ağırlı̆̆ı Ç1, en düşük ise Ç2-Ç3 çeşit ortalamalarından alınmıştır. Ortalama olarak Kral-97 çeşidinin kuru kök ağırlığı aynı istatistiki grupta yer alan Altıkat ve Larende çeşitlerinden \% 19.8 daha fazla olmuştur.

Tuz $(\mathrm{NaCl})$ dozları ortalamalarına göre kuru kök ağırlıkları arasındaki fark önemli bulunmuştur. $\mathrm{NaCl}$ dozlarına göre kuru kök ağırlık ortalamaları 0.081-0.162 mg arasında gerçekleşmiş ve en yüksek $100 \mathrm{mM} \mathrm{NaCl}$ dozundan, en düşük aynı grupta yer alan 150-200 mM NaCl dozlarından elde edilmiştir.

Ç x NaCl interaksiyonlarına göre kuru kök ağırlıkları arasındaki farklar önemli bulunmuştur. Kuru kök ağırlıkları 0.072-0.201 mg arasında gerçekleşirken, en yüksek Ç1- $100 \mathrm{mM} \mathrm{NaCl}$, en düşük aynı grupta yer alan Ç1-200 ve Ç2-200 mM NaCl interaksiyonlarından alınmıştır. En yüksek doz olan $200 \mathrm{mM} \mathrm{NaCl}$ uygulamalarında Larende çeşidi aynı istatistiki grupta yer alan Kral-97 ve Altıkat çeşitlerinden \% 20 daha fazla kuru kök ağırlığına sahip olmuştur.

\subsubsection{Kuru gövde ăğrllğı (mg)}

Tablo 2'ye göre çeşitlerin ortalamalarına göre kuru gövde ağırlıkları arasındaki farklar önemli bulunmuştur. Çeşitlerin kuru gövde ağırlık ortalamaları 0.139-0.217 mg arasında gerçekleşmişken, en yüksek kuru gövde ağırlığı 
AAltuner \& Oral \& Baran

Bazı Arpa ( Hordeum vulgare L. ) Çeşitlerinde Tuz ( $\mathrm{NaCl}$ ) Stresinin Çimlenme Özellikleri Üzerine Etkilerinin Belirlenmesi Ç3, en düşük ise Ç1 çeşit ortalamalarından alınmıştır. Çeşit ortalamalarına göre Larende çeşidi Kral-97 çeşidinden \%35.9 daha fazla kuru gövde ağırlığına sahip olmuştur.

Tuz $(\mathrm{NaCl})$ dozları ortalamalarına göre kuru gövde ağırlıkları arasındaki fark önemli bulunmuştur. $\mathrm{NaCl}$ dozlarına göre kuru gövde ağırlık ortalamaları 0.124-0.276 mg arasında gerçekleşmiş ve en yüksek kontrol (0) dozundan, en düşük aynı grupta yer alan 150-200 mM NaCl dozlarından elde edilmiştir.

Ç x NaCl interaksiyonlarına göre kuru gövde ağırlıkları arasındaki farklar önemli bulunmuştur. Kuru gövde ağırlıkları 0.081-0.407 mg arasında gerçekleşirken, en yüksek Ç3- kontrol (0), en düşük aynı grupta yer alan Ç1$200 \mathrm{mM} \mathrm{NaCl}$ interaksiyonlarından elde edilmiştir. En yüksek doz olan $200 \mathrm{mM} \mathrm{NaCl}$ uygulamalarında Larende çeşidi Kral-97’ye göre \%52.1 daha fazla kuru gövde ağırlığına sahip olmuştur.

Tablo 2. Arpa (Hordeum vulgare L.) tohumlarında tuz stresinin fide özellikleri üzerine etkisi*

Table 2.The effect of salt stress on seedling characteristics in barley (Hordeum vulgare L.) seeds

\begin{tabular}{|c|c|c|c|c|c|c|c|}
\hline Çeşitler & $\begin{array}{c}\text { Stres } \\
\text { Uygulamaları } \\
\text { Tuz Dozları } \\
(\mathbf{m M}) \\
\end{array}$ & $\begin{array}{l}\text { Kök } \\
\text { uzunluğu } \\
(\mathrm{cm})\end{array}$ & $\begin{array}{l}\text { Gövde } \\
\text { uzunluğu } \\
\text { (cm) }\end{array}$ & $\begin{array}{l}\text { Yaş kök } \\
\text { ağırlığı } \\
\text { (mg) }\end{array}$ & $\begin{array}{l}\text { Yaş gövde } \\
\text { ağırlığı } \\
(\mathrm{mg})\end{array}$ & $\begin{array}{l}\text { Kuru kök } \\
\text { ağırlığı } \\
\text { (mg) }\end{array}$ & $\begin{array}{l}\text { Kuru gövde } \\
\text { ağırlığı } \\
\text { (mg) }\end{array}$ \\
\hline \multirow{5}{*}{ Ç1 } & Kontrol (0) & $10.238 \mathrm{a}$ & $11.644 \mathrm{a}$ & $1.489 \mathrm{a}$ & $1.890 \mathrm{bc}$ & $0.136 \mathrm{c}$ & $0.150 \mathrm{f}$ \\
\hline & 50 & $7.883 \mathrm{c}$ & $9.807 \mathrm{abc}$ & $1.460 \mathrm{a}$ & $1.423 \mathrm{e}$ & $0.153 \mathrm{~b}$ & $0.204 \mathrm{c}$ \\
\hline & 100 & $8.588 \mathrm{~b}$ & $9.689 \mathrm{bc}$ & $1.158 \mathrm{~b}$ & $1.738 \mathrm{c}$ & $0.201 \mathrm{a}$ & $0.136 \mathrm{~h}$ \\
\hline & 150 & $5.413 \mathrm{~h}$ & $5.909 \mathrm{~d}$ & $0.551 \mathrm{~d}$ & $0.884 \mathrm{i}$ & $0.086 \mathrm{ef}$ & $0.121 \mathrm{i}$ \\
\hline & 200 & $2.947 \mathrm{j}$ & $3.909 \mathrm{~h}$ & $0.516 \mathrm{e}$ & $0.820 \mathrm{j}$ & $0.079 \mathrm{~g}$ & $0.081 \mathrm{j}$ \\
\hline Ç1 Ortalama & & $7.014 \mathrm{~A}$ & 8.192 & $1.035 \mathrm{~A}$ & $1.351 \mathrm{~B}$ & $0.131 \mathrm{~A}$ & $0.139 \mathrm{C}$ \\
\hline \multirow{5}{*}{ Ç2 } & Kontrol (0) & $9.488 \mathrm{ab}$ & $11.034 \mathrm{abc}$ & $1.270 \mathrm{ab}$ & $2.068 \mathrm{ab}$ & $0.113 \mathrm{~d}$ & $0.272 \mathrm{~b}$ \\
\hline & 50 & $6.757 \mathrm{e}$ & $11.589 \mathrm{a}$ & $0.810 \mathrm{c}$ & $1.339 \mathrm{f}$ & $0.090 \mathrm{e}$ & $0.188 \mathrm{~d}$ \\
\hline & 100 & $6.233 \mathrm{f}$ & $9.521 \mathrm{bc}$ & $1.202 \mathrm{~b}$ & $1.495 \mathrm{~d}$ & $0.158 \mathrm{~b}$ & $0.187 \mathrm{~d}$ \\
\hline & 150 & $3.403 \mathrm{i}$ & $5.034 \mathrm{e}$ & $0.433 \mathrm{f}$ & $1.049 \mathrm{~h}$ & $0.088 \mathrm{e}$ & $0.144 \mathrm{~g}$ \\
\hline & 200 & $3.044 \mathrm{j}$ & $2.840 \quad \mathrm{i}$ & $0.189 \mathrm{~g}$ & $0.543 \mathrm{k}$ & $0.072 \mathrm{~g}$ & $0.123 \mathrm{i}$ \\
\hline Ç2 Ortalama & & 5.785 B & 8.004 & $0.781 \mathrm{~B}$ & $1.299 \mathrm{~B}$ & 0.104 B & 0.183 B \\
\hline \multirow{5}{*}{ Ç3 } & Kontrol (0) & $9.233 \mathrm{ab}$ & $11.200 \mathrm{ab}$ & $1.351 \mathrm{ab}$ & $2.326 \mathrm{a}$ & $0.117 \mathrm{~d}$ & $0.407 \mathrm{a}$ \\
\hline & 50 & $8.426 \mathrm{~b}$ & $10.200 \mathrm{abc}$ & $1.239 \mathrm{~b}$ & $1.925 \mathrm{~b}$ & $0.111 \mathrm{~d}$ & $0.211 \mathrm{c}$ \\
\hline & 100 & $7.256 \mathrm{~d}$ & $9.262 \mathrm{c}$ & $1.218 \mathrm{~b}$ & $1.302 \mathrm{f}$ & $0.127 \mathrm{c}$ & $0.183 \mathrm{de}$ \\
\hline & 150 & $5.821 \mathrm{~g}$ & $4.462 \mathrm{~g}$ & $0.197 \mathrm{~g}$ & $0.808 \mathrm{j}$ & $0.082 \mathrm{f}$ & $0.117 \mathrm{ij}$ \\
\hline & 200 & $5.799 \mathrm{~g}$ & $4.800 \mathrm{f}$ & $0.823 \mathrm{c}$ & $1.242 \mathrm{~g}$ & $0.094 \mathrm{e}$ & $0.169 \mathrm{e}$ \\
\hline Ç3 Ortalama & & $7.307 \mathrm{~A}$ & 7.985 & 0.966 A & $1.521 \mathrm{~A}$ & 0.106 B & $0.217 \quad A$ \\
\hline \multirow{5}{*}{$\begin{array}{c}\text { Tuz Dozları } \\
\text { Ortalama } \\
(\mathbf{m M})\end{array}$} & Kontrol (0) & $9.653 \mathrm{~A}$ & $11.293 \mathrm{~A}$ & $1.37 \mathrm{~A}$ & $2.094 \mathrm{~A}$ & $0.121 \mathrm{~B}$ & $0.276 \mathrm{~A}$ \\
\hline & 50 & $7.688 \mathrm{~B}$ & $105.31 \mathrm{~A}$ & $1.169 \mathrm{~B}$ & $1.562 \mathrm{~B}$ & $0.117 \mathrm{~B}$ & $0.201 \mathrm{~B}$ \\
\hline & 100 & $7.359 \mathrm{~B}$ & $9.490 \quad \mathrm{~B}$ & $1.192 \mathrm{~B}$ & $1.511 \mathrm{~B}$ & $0.162 \mathrm{~A}$ & $0.168 \mathrm{C}$ \\
\hline & 150 & $4.879 \mathrm{C}$ & $5.135 \mathrm{C}$ & $0 . .393 \mathrm{D}$ & $0 . .913 \mathrm{C}$ & $0.085 \mathrm{C}$ & $0.127 \mathrm{D}$ \\
\hline & 200 & $3.929 \mathrm{D}$ & $3.849 \quad \mathrm{D}$ & $0 . .509 \mathrm{C}$ & $0.868 \mathrm{C}$ & $0.081 \mathrm{C}$ & $0.124 \mathrm{D}$ \\
\hline CV (\%) & & 7.626 & 11.074 & 10.948 & 8.387 & 9.415 & 17.022 \\
\hline LSD $_{0.05}$ & & 0.492 & 0.859 & 0.097 & 0.112 & 0.01 & 0.029 \\
\hline
\end{tabular}

Ç1: Kral 97, Ç2: Altıkat, Ç3: Larende

*Ortalamalar arasındaki fark LSD (0.05) çoklu karşılaştırma metoduyla $\mathrm{P}<0.05$ seviyesinde değerlendirilmiştir. Aynı sütunda aynı harfle gösterilen ortalamalar arasında istatistiki olarak bir fark yoktur.

**Tuz $(\mathrm{NaCl})$ dozları ortalamalarının aynı sütunda aynı harfle gösterilen değerleri arasında istatistiki olarak bir fark yoktur.

Arpa çeşitlerinde uygulanan tuz dozlarının bazı çimlenme ve fide parametreleri üzerindeki etkileri şekillerde verilen grafiklerde gösterilmektedir. Buna göre tuz dozları arttıkça kök uzunlukları ve gövde uzunluklarının düştüğü görülmektedir. $200 \mathrm{mM} \mathrm{NaCl}$ dozunda Larende çeşidinin kök uzunluğunun diğer çeşitlerden \% 48.3 daha 
fazla olduğu, benzer şekilde Larende çeşidinin gövde uzunluğunun Altıkat çeşidinden \% 40.8 daha fazla gerçekleştiği görülmektedir (Şekil 1). Çalışmamızda tespit edilen artan $\mathrm{NaCl}$ dozlarının kökçük ve gövde uzunluğunu azalttığı Güngör ve ark. (2017), Doğan ve Budaklı Çarpıcı (2016) Chauhan ve ark. (2016) ve Öner ve ark. (2018) tarafından da açıklanmıştır. Kökçük uzunluğunun bitkilerin tuza karşı toleransını belirleyen önemli bir özellik olduğu belirtilmektedir (Demiroğlu Topçu ve Özkan, 2020).

Araştırmada tuz dozlarındaki artışın kuru kök ve kuru gövde ağırlı̆̆ını düşürdüğü, ancak kuru gövde ağırlığının tuz uygulamalarından nispeten daha az etkilendiği gözlenmiştir. Kral-97 çeşidi $100 \mathrm{mM}$ tuz dozunda kontrolden ve diğer çeşitlerde daha fazla kuru kök ağırlığına sahip olmasına rağmen, $200 \mathrm{mM}$ tuz uygulamalarında Larende çeşidinin diğer çeşitlerden \% 20 daha fazla kuru kök ağırlı̆̆ına sahip olduğu görülmüştür. Başlangıçta en fazla ağırlığa sahip olan Larende çeşidinin $200 \mathrm{mM}$ tuz uygulamalarında Kral-97 çeşidinden \% 52.1 daha fazla gövde kuru ağırlığına ulaştı̆̆ı anlaşılmaktadır (Şekil 2).

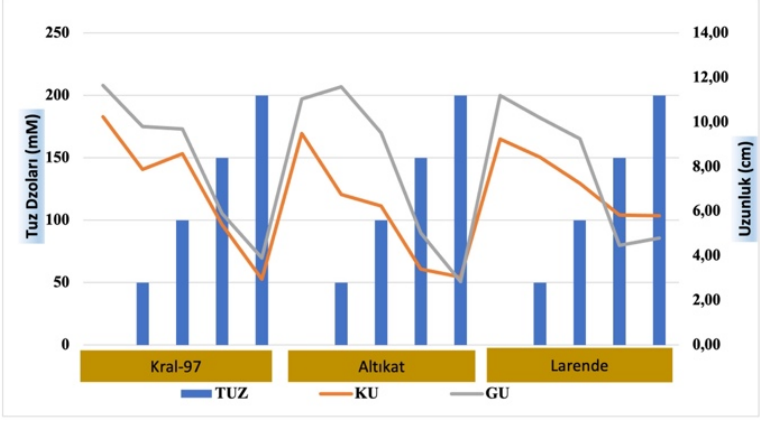

Figure 1. Effects of salt doses on root length $(K U)$ stem length $(G U)$ in cultivars

Şekil 1. Tuz dozlarının çeşitlerde Kök Uzunluğu (KU) ve Gövde Uzunluğu (GU) üzerine etkileri

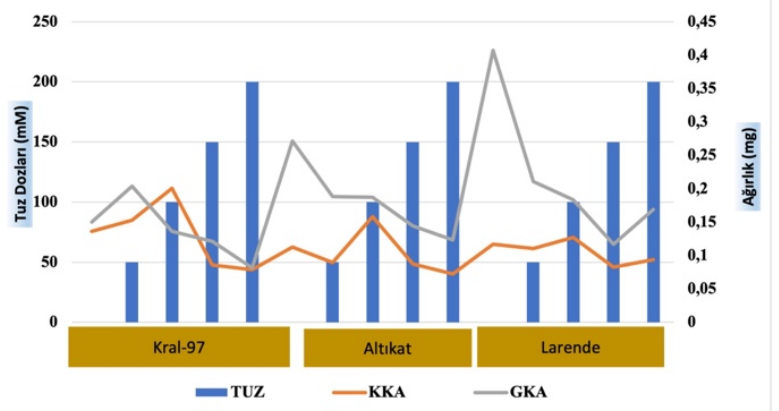

Figure 2. The effects of salt doses on root dry weight (KKA) and and stem dry weight (GKA)

Şekil 2. Tuz dozlarının çeşitlerde Kök Kuru Ă̆ırlı̆̆ı (KKA) ve Gövde Kuru Ăğırlı̆̆ (GKA) üzerine etkileri

$\mathrm{Bu}$ çalışmada tespit edilen tuz konsantrasyonlarının etkisinin önemli olduğu, artan $\mathrm{NaCl}$ konsantrasyonlarının kuru kök ve kuru gövde ağırlığını olumsuz etkilediği, Benlioğlu ve Özkan (2015), Singh ve Jakar (2018), Fardus ve ark. (2018), Ali ve ark., (2012), Öner ve ark. (2018), Zadeh ve ark. (2015) ve Tunçtürk ve ark. (2019) tarafindan da tespit edilmiştir.

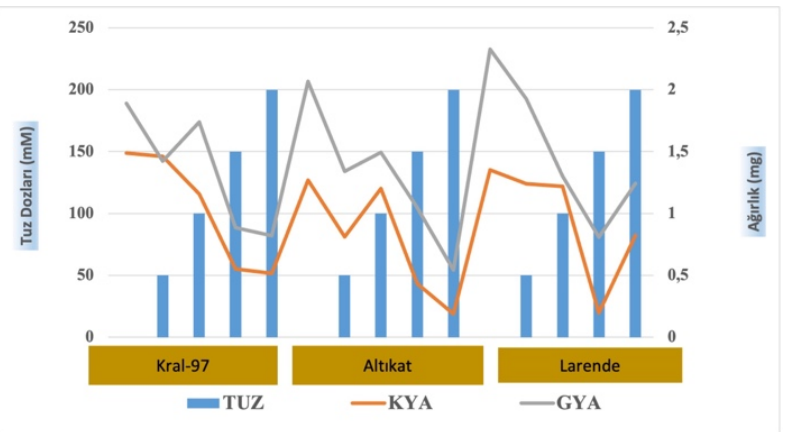

Figure 3. The effects of salt doses on Root Age Weight (KYA) and Body Age Weight (GYA) in cultivars

\section{Şekil 3. Tuz dozlarının çeşitlerde Kök Yaş Ă̆ırlı̆̆ı (KYA) ve Gövde Yaş Ă̆ırlı̆̆ $(G Y A)$ üzerine etkileri}

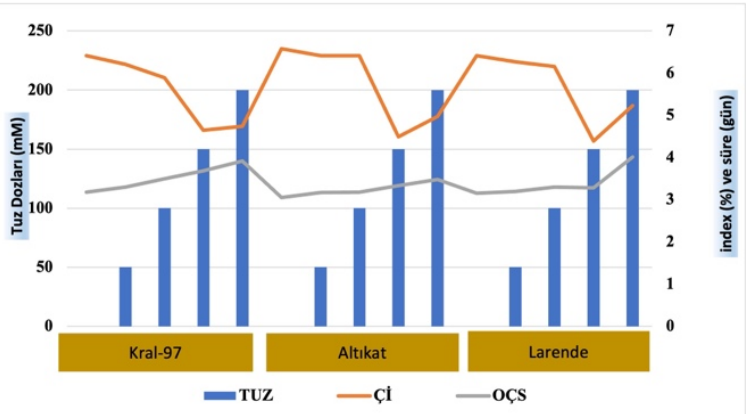

Figure 4. The effects of salt doses on the Germination Index (CL) and Average Germination Time $(O C ̧ S)$ in cultivars

\section{Sekil 4. Tuz dozlarının çeşitlerde Çimlenme Indeksi (ÇI) ve Ortalama Çimlenme Süresi (OÇS) üzerine etkileri}

Buna benzer şekilde tuz dozu uygulamalarının genel olarak gövde yaş ağırllğı ve kök yaş ağırlı̆̆ parametrelerinde düşüşe neden olduğu, ancak diğer çeşitlere nispeten Kral-97 çeşidinde bu parametrelerin daha az etkilendiği gözlenmektedir. Bir önceki doza göre $200 \mathrm{mM}$ tuz dozu uygulamasında diğer çeşitlerden farklı olarak Larende çeşidinin kök yaş ağırlı̆̆ ve gövde yaş ağırlığı özelliklerinde artış olduğu görülmektedir. Bu yönüyle Larende çeşidi $200 \mathrm{mM}$ tuz dozunda Altıkat çeşidinden \%77.0 daha fazla kök yaş ağırlı̆̆ı ve $\% 56.3$ daha fazla gövde yaş ağırlı̆̆ı oluşturduğu anlaşılmaktadır (Şekil 3). Bu araştırmada tespit edildiği şekilde artan $\mathrm{NaCl}$ 
AAltuner \& Oral \& Baran

Bazı Arpa ( Hordeum vulgare L. ) Çeşitlerinde Tuz (NaCl) Stresinin Çimlenme Özellikleri Üzerine Etkilerinin Belirlenmesi konsantrasyonlarının yaş kök ve yaş gövde ağırlığını olumsuz etkilediği Benlioğlu ve Özkan (2015), Singh ve Jakar (2018), Fardus ve ark. (2018), Ali ve ark. (2012), Zadeh ve ark. (2015) ve Tunçtürk ve ark. (2019) tarafindan da ifade edilmiştir. Bu durum tuzluluğun yüksek olduğu alanlarda yaşanan fizyolojik kuraklığın sürgün yaş ağırlığını düşürmesi nedeniyle oluşmaktadır (Demiroğlu Topçu ve Özkan, 2020).

Tüm çeşitlerde tuz uygulamalarının çimlenme indeksini düşürdüğü ve $150 \mathrm{mM}$ tuz uygulamalarında en düşük seviyeye indiği gözlenirken, artan tuz dozlarıyla ortalama çimlenme süresinin de artış gösterdiği ve ortalama çimlenme süresini en fazla geciktiren uygulamanın $200 \mathrm{mM}$ tuz dozu olduğu görülmektedir (Şekil 4). Çalışmamızda belirlendiği gibi artan tuz dozlarının ortalama çimlenme süresini uzattığı, çimlenme indeksini ve hassaslık indeksini olumsuz etkilediği Tunçtürk ve ark. (2019), Güngör ve ark., (2017) ve Sanam ve ark., (2014) tarafından da belirlenmiştir.

Tuz toleransı çeşitlere göre değişmekte ve tuzlu alanlarda yüksek toleransa sahip çeşitlerin tercih edilmesi gerekmektedir (El Goumi ve ark., 2014). Tuz dozu ortalamalarına göre, kontrol grubuyla kıyaslandığında tuz uygulamalarından en fazla etkilenen özelliğin ortalama çimlenme süresi (\% 82.1), en az etkilenen özelliğin ise kök yaş ağırlığı (\% 28.7) olduğu anlaşılmaktadır (Tablo 1 ve Tablo 2).

\section{Sonuç ve Öneriler}

Üç arpa çeşidine (Kral-97: Ç1, Altıkat: Ç2 ve Larende: Ç3) uygulanan bazı NaCl (kontrol (0)-50-100-150$200 \mathrm{mM}$ ) dozlarının, tohumların çimlenme özellikleri ve fide parametrelerini belirlemek üzere gerçekleştirilen bu çalışmanın sonuçlarına göre;

Çimlenme parametreleri yönünden; çeşitlerin sadece çimlenme indeksi ve ortalama çimlenme süresi üzerindeki etkileri ve oluşan farklar önemli bulunmuştur. Tuz dozlarının bütün çimlenme parametreleri çimlenme oranı, (çimlenme gücü, ortalama çimlenme sürresi, çimlenme indeksi ve hassaslık indeksi) üzerindeki etkileri ve oluşan farklar önemli bulunmuştur. Çeşitler ve $\mathrm{NaCl}$ interaksiyonlarının ise tüm parametrelerde oluşan farklar üzerindeki etkileri yine önemli bulunmuştur. Ortalamalara göre en düşük çimlenme gücü ve çimlenme oranlarının $150 \mathrm{mM}$ $\mathrm{NaCl}$ uygulamalarından alındığı ve bu nedenle bu iki özelliğin kontrole (0) göre \% 15.56 oranında düştüğü görülmüştür. Fide parametreleri yönünden; çeşitlerin gövde uzunluğu üzerindeki etkileri önemsiz geriye kalan tüm parametreler üzerindeki etkileri önemli bulunmuşken, tuz dozlarının ve çeşitler ile $\mathrm{NaCl}$ interaksiyonlarının tüm parametrelerde (kök uzunluğu, gövde uzunluğu, kök yaş ağırlığı, gövde yaş ağırlığı, kök kuru ağırlığı ve gövde kuru ağırlı̆̆1) oluşan farklar üzerindeki etkileri önemli bulunmuştur. Tuz dozu ortalamalarına göre, kontrol grubuyla kıyaslandığında tuz uygulamalarından en fazla etkilenen özelliğin ortalama çimlenme süresi (\% 82.1), en az etkilenen özelliğin ise kök yaş ağırlığı (\% 28.7) olduğu görülmüştür.

Artan tuz dozlarının bütün parametreler üzerinde olumsuz etkide bulunduğu gözlenmiştir. Larende çeşidinin tüm özellikleri yönünden tuza daha dayanıklı bir performans gösterdiği bunu genel olarak Kral-97 çeşidinin takip ettiği tespit edilmiştir. Bu sebeple tuz seviyesi yüksek alanlarda bu iki çeşidin yetiştirilmesi önerilmekte ve benzer çalışmaların arazi koşullarında da yürütülmesi tavsiye edilmektedir. 
Kaynakça

Akıncı, İ.E., Calışkan, U. (2010). Effect of lead on seed germination and tolerance levels in some summer vegetables. Ekoloji Dergisi, 19, 164172 .

Ali, H.M., Siddiqui, M.H., Basalah, M.O., Al-Whaibi, M.H., Sakran, A.M., Al-Amri, A. (2012). Effects of gibberellic acid on growth and photosynthetic pigments of Hibiscus sabdariffa L. under salt stress. African Journal of Biotechnology Vol. 11(4), pp. 800-804.

Ali, S., Rizwan, M., Qayyum, M.F., Ok, Y.S., Ibrahim, M., Riaz, M., Shahzad, A.N. (2017). Biochar soil amendment on alleviation of drought and salt stress in plants: a critical review. Environmental Science and Pollution Research, 24(14): 12700-12712.

Altan, A., Yağcı, S., Maskan, M., Göğü,ş F. (2006). Türkiye 9. Gıda Kongresi; 24-26 Mayıs 2006, Bolu, $495-498$.

Altuner, F., Oral, E., Ülker, M. (2018). Bazı Arpa (Hordeum vulgare L.) Çeşitlerinde Verim ve Verim Unsurlarının Belirlenmesi. Bahri Dağdaş Bitkisel Araştırma Dergisi, 7(2): 11-22.

Anonim (2017). Türkiye İstatistik Kurumu, http://www.tuik.gov.tr/PreTablo.do?alt_id=100. (Erişim tarihi: 18.04.2017).

Aras, İ., Keskin, B. (2018). The Effects of Different Irrigation Water Salinity Levels on Some Silage Sorghum (Sorghum sp.) Types. Igdir University Journal of the Institute of Science ,8(1): 279-288.

Askari, H., Kazemitabar, S.K., Zarrini, H.N., Saberi, M.H. (2016). Salt tolerance assessment of barley (Hordeum vulgare L.) genotypes at germination stage by tolerance indices. Open Agriculture, 1:37-44.

Benlioğlu, B., Özkan, U. (2015). Bazı arpa çeşitlerinin (Hordeum vulgare L.) çimlenme dönemlerinde farklı dozlardaki tuz stresine tepkilerinin belirlenmesi. Tarla Bitkileri Merkez Araştırma Enstitüsü Dergisi, 24(2): 109-114.

Chauhan, A., Rajput, N., Kumar, D., Kumar, A., Chaudhry, A.K. (2016). Effect of different salt concentration on seed germination and seedling growth of different varieties of oat (Avena sativa L.). Int J Inf Res Rev, 3(7): 2627-2632.

Çakmakçı, S., Dallar, A. (2019). Farklı Sıcaklık ve Tuz Konsantrasyonlarının Bazı Silajlık Mısır Çeşitlerinin Çimlenme Özellikleri Üzerine Etkileri. Tekirdağ Ziraat Fakültesi Dergisi, 16(2), 121-132.

Çölkesen, M., Öktem, A., Engin, A., Öktem, G., Demirbağ, V., Yürürdurmaz, C., Çokkızgın, A. (2002). Bazı Arpa Çeşitlerinin (Hordeum vulgare L.) Kahramanmaraş ve Şanlıurfa Koşullarında Tarımsal ve Kalite Özelliklerinin Belirlenmesi. KSÜ Fen ve Mühendislik Dergisi 5(2): 76-87.

Dadaşoğlu, E., Ekinci, M. (2013). Farklı Sıcaklık Dereceleri, Tuz Ve Salisilik Asit Uygulamalarının Fasulye (Phaseolus vulgaris L.) Tohumlarında Çimlenme Üzerine ～Etkisi.” Atatürk Üniversitesi Ziraat Fakültesi Dergisi, 44(2): 145-150.

Demirbaş, S., Balkan, A. (2018). Tuz Stresi Koşullarında Bazı Tritikale Çeşitlerinin Hidrojen Peroksit Ön Uygulamasına Tepkileri. Tekirdăg Ziraat Fakültesi Dergisi, 15(2), 5-13.

Demiroğlu Topçu, G., Özkan, Ş.S. (2020). Effects of Different Salt Sources and Concentrations on Germination Parameters of Barley (Hordeum vulgare L.) Seeds. ISPEC Journal of Agricultural Sciences, 4(3), 456-467.

Doğan, R., Budaklı Çarpıcı, E. (2016). Farklı Tuz Konsantrasyonlarının Bazı Tritikale Hatlarının Çimlenmesi Üzerine Etkileri.” Kahramanmaraş Sütçü İmam Üniversitesi Doğa Bilimleri Dergisi 19(2): 130-135.

Düzgüneş, O., Kesici, T., Kavuncu, O., Gürbüz, F. (1987). Araştırma ve deneme metotları. İstatistik Metotları-II. Ankara Universitesi, Ziraat Fakültesi Yayınları, s.1021, 295.

El Goumi, Y., Fakiri, M., Lamsaouri, O., Benchekroun, M. (2014). Salt stress effect on seed germination and some physiological traits in three Moroccan barley (Hordeum vulgare L.) cultivars. J. Mater. Environ. Sci., 5(2):625-632.

FAO (2017). Barley crops production. Food and Agriculture Organization (FAO) of the United Nations, Rome, Italy. Available http://faostat.fao.org/site/567/default.aspx\#ancor. (Erişim tarihi: 18.04.2017).

Fardus, J., Matin, M.A., Hasanuzzaman, M., Hossain, M.A. (2018). Salicylic acid-induced improvement in germination and growth parameters of wheat under salinity stress. The Journal of Animal and Plant Sciences, 28 (1): 197-207.

Ghaffarzadegan T., Zhong Y., Hållenius, F.F., Nyman M. 2018. Effects of barley variety, dietary fiber and $\beta$-glucan content on bile acid composition in cecum of rats fed low-and high-fat diets. The Journal of Nutritional Biochemistry, 53: 104-110.

Güldüren, Ş., Elkoca, E.(2012). Kuzey Doğu Anadolu Bölgesi ve Çoruh Vadisi’nden toplanan bazı fasulye (Phaseolus vulgaris L.) genotiplerinin çimlenme döneminde tuza toleransları. Atatürk Üniversitesi Ziraat Fakültesi Dergisi, 43(1):29-41.

Güngör, H., Çıkılı, Y., Dumlupınar, Z. (2017). Bazı ticari ve yerel yulaf genotiplerinin çimlenme ve fide gelişimi üzerine tuz stresinin etkileri. KSÜ Doğa Bilimleri Dergisi, 20, 263-267.

Horie, T., Karahara, I., Katsuhara, M. (2012). Salinity tolerance mechanisms in glycophytes: An overview with the central focus on rice plants. Rice, 5(1), 1-18.

Kalaji, H.M., Bosa, K., Kościelniak, J., Żuk-Gołaszewska, K. (2011). Effects of salt stress on photosystem II efficiency and CO2 assimilation of two Syrian barley landraces. Environmental and Experimental Botany, 73: 64-72. 
AAltuner \& Oral \& Baran

Bazı Arpa ( Hordeum vulgare L. ) Çeşitlerinde Tuz (NaCl) Stresinin Çimlenme Özellikleri Üzerine Etkilerinin Belirlenmesi

Kumar, D.S., Kumar, P.S., Rajendran, N.M., Anbuganapathi, G. (2013). Compost maturity assessment using physicochemical, solid-state spectroscopy, and plant bioassay analysis. Journal of agricultural and food chemistry, 61(47): 11326-11331.

Machado, R.M.A., and Serralheiro, R.P. (2017). Soil salinity: effect on vegetable crop growth. Management practices to prevent and mitigate soil salinization. Horticulturae, 3(2): 30 .

Metwali, E.M., Hemaid, I.A.S., Al-Zahrani, H.S., Howlader, S.M., Fuller, M.P. (2014). Influence of different concentrations of salt stress on in vitro multiplication of some fig (Ficus carcia L.) cultivars. Life Science Journal, 11(10).

Mian A., Oomen R.J., Isayenkov S., Sentenac H., Maathuis F.J., Véry A.A. (2011). Over-expression of an Na+-and K+-permeable HKT transporter in barley improves salt tolerance. The Plant Journal, 68(3): 468-479.

Miano, A.C., Forti, V.A., Abud, H.F., Gomes-Junior, F.G., Cicero, S.M., Augusto, P.E.D. (2015). Effect of ultrasound technology on barley seed germination and vigour. Seed Science and Technology, 43(2), 297-302.

Milivojević, M., Ripka, Z., Petrović, T. (2018). ISTA rules changes in seed germination testing at the beginning of the 21 st century. Journal on Processing and Energy in Agriculture, 22(1): 40-45.

Öner, F., Özkorkmaz, F., Yılmaz, N. (2018). Tuz Stresi Altında Gibberellik Asit Uygulamalarının Yulafta Bazı Çimlenme Parametreleri Üzerine Etkisi. International Journal of Agricultural and Natural Sciences (IJANS) E-ISSN: 2651-3617, 1(1):33-35.

Parihar, P., Singh, S., Singh, R., Singh, V.P., Prasad, S.M. (2015). Effect of salinity stress on plants and its tolerance strategies: a review. Environmental Science and Pollution Research, 22(6): 4056-4075.

Park, H.S., Choi, H.J., Kim, K.H. (2013). Effect of supercritical CO2 modified with water cosolvent on the sterilization of fungal sporecontaminated barley seeds and the germination of barley seeds. Journal of Food Safety, 33(1): 94-101.

Rejeb, I.B., Pastor, V., Mauch-Mani, B. (2014). Plant responses to simultaneous biotic and abiotic stress: molecular mechanisms. Plants, 3(4): 458-475.

Sanam, S.A., Pirdashti, M.H., Mirjalili, M.H., Hashempour, A. (2014). Effect of exogenous nitric oxide on germination and some of biochemical characteristics of purple coneflower (Echinacea purpurea L.) in saline condition. Zīst/shināsī-i Giyāhī-i İrān, Iss 20, Pp 55-74.

Singh, S., Jakhar, S. (2018). 24-Epibrassinolide mediated changes on germination and early seedling parameters of Vigna mungo (L). Hepper Var. Shekhar-2 under Salinity Stress. Pertanika J. Trop. Agric. Sci. 41 (1): 485-494.

Taşçı, R., Bayramoğlu, Z. (2017). Arpa Çeşitlerinin Üretim, Pazarlama ve İşleme Açısından Önemi. Türk Tarım - Gıda Bilim ve Teknoloji Dergisi, 5(8): 923-934.

Tuncturk, R., Kipcak, S., Ghiyasi, M., \& Tuncturk, M. (2019). The determination of gibberellic acid effects on seed germination of Echinacea purpurea (L.) Moench under salt stress. International Journal of Agriculture Environment and Food Sciences, 3(2), 101-105.

Yıldız, S., Karagöz, F.P., Dursun, A. (2017). Giberellik Asit Ön Uygulamasına Tabi Tutulmuş Hüsnüyusuf (Dianthus barbatus L.) Tohumlarının Tuz Stresinde Çimlenmesi. Atatürk Üniversitesi Ziraat Fakültesi Dergisi, 48(1): 1-7.

Zadeh, S.Y., Ramin, A.A, Baninasab, B. (2015). Effect of gibberellic acid, stratification and salinity on seed germination of Echinacea purpureacv. Magnus. Herba Polonica; 61(3): 13-22. 